\title{
Paediatric Tracheal Stenosis-A 10-Year Experience from a Tertiary Paediatric Otolaryngology Unit
}

\author{
Jian Li Tan* and Henry Kun Kiaang Tan \\ Department of Otolaryngology, KK Women's and Children's Hospital, 100 Bukit Timah Road, Singapore
}

Submission: May 18, 2018; Published: May 25, 2018

*Corresponding author: J L Tan, Department of Otolaryngology, KK Women's and Children's Hospital, 100 Bukit Timah Road, Singapore 229899, Singapore, Email: jianli.tan@mohh.com.sg

\section{Introduction}

Tracheal stenosis is a very rare life-threatening airway disease [1]. The incidence is estimated to be 1 in 64,500 , with a mortality rate as high as $79 \%$ before the advent of current surgical techniques [2,3]. In the paediatric population, tracheal stenosis may be congenital or acquired, of which the former predominates. Children present with a variety of symptoms ranging from asymptomatic to biphasic stridor on exertion, desaturation or cardiac arrest. Congenital tracheal stenosis is often associated with other congenital anomalies, specifically cardiovascular, pulmonary and esophageal anomalies [4]. The management of these patients often involves a multi-disciplinary team approach with close interaction with family members, brought about by multiple admissions, procedures and surgeries [1-3].

Acquired tracheal stenosis is less commonly encountered in the paediatric population. Traumatic or prolonged intubation more commonly results in subglottic stenosis rather than tracheal stenosis, as the subglottis is the narrowest part of the paediatric airway. The subglottis is also often where the cuff of the endotracheal tube sits, making the mucosa prone to abrasion from the movement of an inflated cuff. The juvenile trachea with its much smaller diameter compared to the adult, has a narrower window of tolerance before symptoms arise from surgical instrumentation or traumatic intubation.

As tracheal stenosis is not commonly encountered, there is a paucity of large-scale studies on this topic. There is currently no gold standard treatment and a variety of techniques have been used to correct this condition. This paper aims to add to the existing body of literature, by reviewing a 10-year experience in managing paediatric tracheal stenosis in a tertiary paediatric hospital in Singapore.

\section{Methods}

This study was approved by the Sing health Institutional Review Board as a retrospective case series, with waiver of informed consent. All paediatric patients $(<16$ years of age) with the diagnosis of tracheal stenosis who underwent diagnostic microlaryngobronschoscopy (MLB) in KK Women's and Children's Hospital, Singapore between January 2007 and December 2016 were included in this study. Patient data was obtained from the hospital operating theatre records system. The patients' medical records were retrieved and reviewed for the demographic data, comorbidities, presenting symptoms and management strategies. Other data such as the need for tracheostomy, ventilator support, degree of tracheal stenosis and final outcomes were also collecte $0 \mathrm{~d}$.

\section{Results}

A total of 19 children underwent MLB and were diagnosed with tracheal stenosis; 14 were congenital and 5 were acquired. There were 10 males and 9 females in this series. The age at the time of diagnosis ranged from one day to 15 years old. The mean age at the time of diagnosis for congenital tracheal stenosis was 10.4 months and 58.1 months for acquired tracheal stenosis. There were two patients with VACTERL association, two with abnormal karyotypes and one with Pierre-Robin syndrome. The remaining 14 cases were not associated with any syndromes or declined further genetic workup. At the time of data collection for this study, there were 5 mortalities. These patients were all diagnosed with congenital tracheal stenosis. The age of mortality ranged from 2 days to 13 months, the mean being 4 months [4].

The most common presenting symptom was repeated desaturation $(n=10,52.6 \%)$, followed by biphasic stridor or stridor on exertion $(n=7,36.8 \%)$. Two patients were completely asymptomatic of the asymptomatic patients, one had MLB for suspected foreign body in the airway and the other had MLB because of difficulty in passing an age-appropriate endotracheal tube during intubation for an elective surgery. All the patients in the series underwent MLB either pre-operatively as a diagnostic procedure or post-operatively to evaluate the patency of the trachea. The average number of interventions (surgical correction or MLB evaluation and intervention) underwent by this case series is 5.47 procedures per patient (range from 1 


\section{Global Journal of Otolaryngology}

to 19). The most common intervention is MLB evaluation with or without intervention, which averages 4.16 procedures per patient (range from 1 to 17 ).

During the initial MLB, the patients were given a percentage occlusion based on the surgeon's visual estimation. There is not universal classification system for the degree of tracheal stenosis so Cotton Myer grading was used as a proxy. There were 12 patients given grade 2 and 3 with equal distribution while 7 patients were given grade 1 (Figure 1). Eleven patients (57.9\%) underwent primary procedures to correct/improve the tracheal stenosis. The most common procedure performed was a slide tracheoplasty $(n=6)$, followed by endoscopic dilatation with carrot bougie $(n=3)$ (Figure $2 \& 3$ ) (table 1).

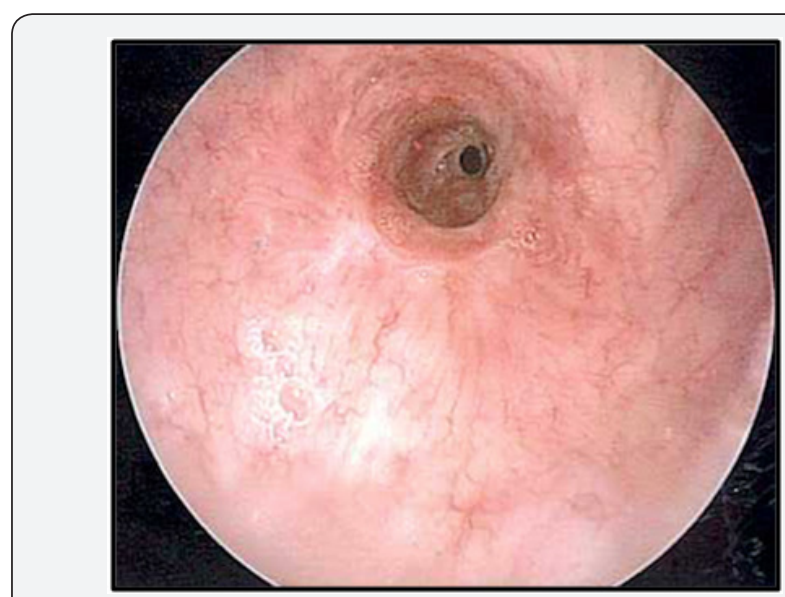

Figure 1: MLB photo of a patient with an acquired tracheal stenosis.

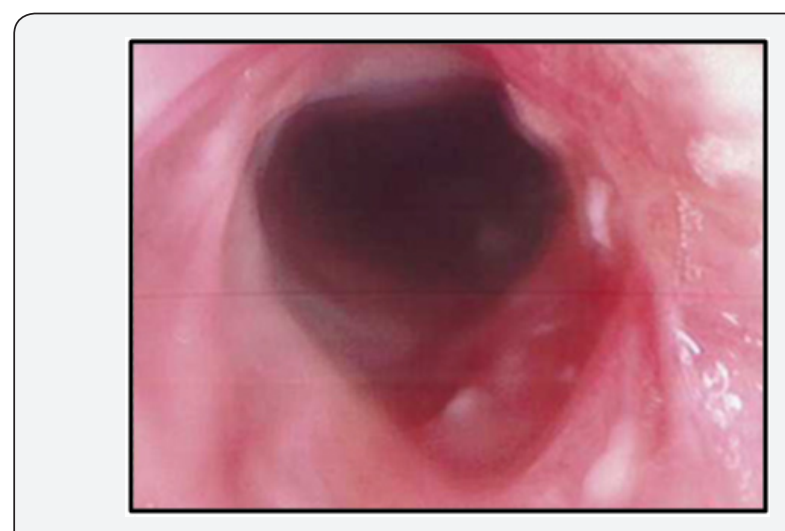

Figure 2: Patient shown in Figure 1 with a stenotic segment 2 weeks after the 1 st dilatation.

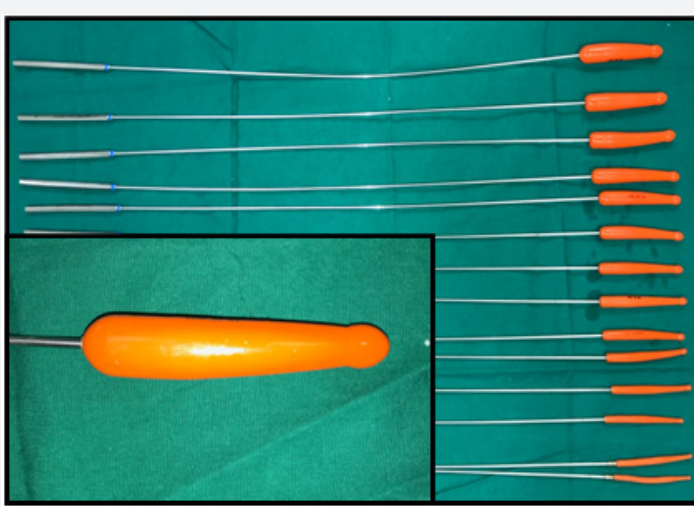

Figure 3: Carrot bougies of different sizes used for endoscopic dilatation of tracheal stenosis, inset figure - magnified view of dilator tip.

Table 1: Patient demographics.

\begin{tabular}{|c|c|}
\hline Demographic & No. of patients (\%) \\
\hline Gender & $10(52.6)$ \\
\hline Male & $9(47.4)$ \\
\hline Female & $14(73.7)$ \\
\hline Syndromic/Genetic associations & $2(10.5)$ \\
\hline None & $2(10.5)$ \\
\hline Abnormal karyotypes & $1(5.26)$ \\
\hline VACTERL assocation & $14(73.7)$ \\
\hline Pierre-Robin Sequence & $5(26.3)$ \\
\hline Type of tracheal stenosis & $10(52.6)$ \\
\hline Congenital tracheal stenosis & $7(36.8)$ \\
\hline Acquired tracheal stenosis & $2(10.5)$ \\
\hline Presenting symptoms & \\
\hline Desaturations & 0 \\
\hline Stridor & $6(31.6)$ \\
\hline Asymptomatic & \\
\hline Percentage of occlusion (Cotton Myer classification) & \\
\hline No detectable lumen & \\
\hline $71-99 \%$ occlusion & \\
\hline
\end{tabular}


Global Journal of Otolaryngology

\begin{tabular}{|c|c|}
\hline $51-70 \%$ occlusion & $6(31.6)$ \\
\hline $0 \%-50 \%$ occlusion & $7(36.8)$ \\
\hline Age at mortality & $\mathrm{N}=5$ \\
\hline $1-28$ days & $2(40)$ \\
\hline $1-12$ months & $2(40)$ \\
\hline$>12$ months & $1(20)$ \\
\hline
\end{tabular}

\section{Discussion}

A total of 14 cases of congenital tracheal stenosis were identified during the period of study. Correlating with the live birth rate in our institution over the study period, the incidence of congenital tracheal stenosis is 1.18 in 10,000 live births. This, however, may be an underestimate of the actual incidence, as some cases of severe tracheal stenosis may have resulted in stillborn, miscarried or terminated pregnancies. The number of cases in this series is also similar to a retrospective study $(n=11)$ performed in our institution which collected data from January 1999 to December 2008 [5]. It suggests that the incidence may be increasing despite a declining birth rate in Singapore. This may be due to better perinatal healthcare leading to better detection rates.

All the congenital tracheal stenosis patients in this series were associated with cardiovascular, pulmonary and/or esophageal anomalies. This is not unexpected, as these organs are closely related during embryological development. The most common anomaly is a left pulmonary artery sling, followed by a trial septal defect and patent ductus arteriosus. These anomalies are also cited as the most common cardiovascular anomalies associated with congenital tracheal stenosis in a series by Chao YC et al [6]. None of the congenital tracheal stenosis cases were identified on antenatal screening. This could be because identifying a trachea that is not air-filled in utero is challenging using existing prenatal imaging techniques. Conversely, many of the cardiovascular and pulmonary abnormalities were detected on antenatal scans. This highlights the importance of having a high index of suspicion for congenital tracheal stenosis in a neonate with cardiovascular anomalies presenting with stridor and/or desaturations.

The mortality rate of congenital tracheal stenosis in this study is $35.7 \%$. Apart from tracheal stenosis, 4 of these 5 patients had other major anomalies, such as complex cyanotic heart disease, large tracheo-esophageal fistula with laryngotracheal cleft and large diaphragmatic hernia with agenesis of the right main bronchus. In these cases, while tracheal stenosis being a direct threat to the airway contributed significantly to these mortalities, there were often other contributory causes such as sepsis and cardiovascular compromise leading to their demise.

The patient with complex cyanotic heart disease also had an underlying VACTERL association (Vertebral defects, Anal atresia, Cardiac defects, Tracheo-esophageal fistula, Renal anomalies and Limb anomalies), resulting in systemic complications incompatiable with life. After the MLB on the first day of life, the child unfortunately died the following day.

Another patient who died at 2 months of life, had a background of Pierre Robin Sequence and multiple cardiac defects including large ventricular and atrial septal defects, large patent ductus arteriosus and tricuspid valve regurgitation. This patient's eventual cause of death was due to pneumonia.

Two other mortalities occurred in patients who underwent surgery and are further elaborated below. For the patients who underwent corrective surgery for congenital tracheal stenosis in our institution, the average survival was 57 months (range from 2 months to 127 months) with a mortality rate of $9.09 \%$ (2 patients). This mortality rate is comparable globally to other institutions, ranging from 9 to $21 \% 7$. One of the patients underwent slide tracheoplasty and was complicated by a persistent left chylothorax as well as necrotising enterocolitis. This patient succumbed to sepsis eventually. The other patient had a large distal tracheo-esophageal fistula and a laryngotracheal cleft. This patient had a stormy stay in the intensive care unit since birth; underwent multiple attempts at repairing the large tracheo-esophageal fistula. Cardio-respiratory support was also a challenge due to the presence of the fistula; there was air entry into his abdominal system from the positive pressure ventilation, resulting in frequent desaturations. He went through a maximal quota of two Extracorporeal Membrane Oxygenation during the course of his treatment. Eventually, he also succumbed to sepsis after a year of treatment [7].

The most common corrective surgery performed in our institution is a slide tracheoplasty. This surgery was first proposed by Tsang et al [8] in 1989 and over the years has gained acceptance in many institutions because it has an excellent success rate, is easier to perform than traditional tracheal surgeries and requires shorter postoperative hospitalisation [9]. Macchiarini et al confirmed using animal models that this technique offers a doubling of the circumference of the trachea and quadrupling the cross-sectional area [10]. Slide tracheoplasty can provide good long-term outcomes as shown in our series. This result is similar to other studies in the literature which showed good outcomes up to 7 years after slide tracheoplasty [11]. Other techniques reported in the literature include balloon dilatation, lasering, stenting and patch tracheoplasty [12].

Acquired tracheal stenosis is uncommon in the paediatric population. They are often grouped under acquired laryngotracheal stenosis where subglottis stenosis remains the 
most common site of stenosis. These cases are often treated with open surgery such as single or double stage laryngotracheal reconstruction or cricotracheal resection [13]. For the 5 cases of acquired tracheal stenosis, 3 underwent endoscopic dilatation with carrot bougie. The remaining 2 did not undergo any procedure. This difference in management reflects the contrast in pathophysiology of congenital and acquired tracheal stenosis. In congenital tracheal stenosis, the segment of stenosis is usually longer and is stenosed either due to a complete tracheal ring or a vascular sling. These abnormalities are unlikely to respond to endoscopic dilatation. In acquired tracheal stenosis, these stenotic segments are usually secondary to trauma by the cuff or the tip of the endotracheal tube, resulting in short-segment edema, granulation, inflammation or fibrosis. This makes them more amendable to dilatation either by carrot bougie or airway balloon (Figure 3). Although our numbers are small, the high success rate of this technique has led to the conclusion that it should be considered as the first line of treatment in an isolated acquired tracheal stenosis without involvement of the larynx.

MLB remains an important procedure for the diagnosis and treatment of paediatric tracheal stenosis. MLB, performed with an appropriately sized ventilating rigid bronchoscope, allows safe ventilation during inspection. It is vital to perform atraumatically to avoid edema and inflammation which could worsen the stenosis or precipitate acute obstruction [14]. The digitalised images and recordings can also aid the physician in demonstrating the severity of the condition during discussion with the patient's parents. As these patients are frequently managed by a multi-disciplinary team, the images can also be viewed repeatedly and used to improve communication between physicians from different specialities.

Being a retrospective study, the information required for analysis may not be comprehensive. However, the rare nature of this condition makes it difficult for any prospective studies to be performed practically. Neonates with severe tracheal stenosis may not be referred to our paediatric otolaryngology unit and undergo a MLB before expiration. These cases would not have been captured by this study. Although KK hospital is the largest tertiary paediatric institution in Singapore, we have not included data from other institutions in this study. This may affect the accuracy of our results.

\section{Conclusion}

Paediatric tracheal stenosis is a rare but potentially lifethreatening major airway disease. Despite its rarity, it should be considered in a child presenting with stridor or recurrent desaturations with a background of cardio-respiratory anomalies. MLB with or without a ventilating rigid bronchoscope is an important initial diagnostic procedure, with imaging techniques serving as an adjunct for detailed evaluation. While slide tracheoplasty being the mainstay of treatment to correct congenital tracheal stenosis, endoscopic dilatation with or without endotracheal stenting can be considered as the first-line treatment for acquired tracheal stenosis.

\section{References}

1. Loeff DS, Filler RM, Vinograd I, Ein SH, Williams WG, et al. (1988) Congenital tracheal stenosis: a review of 22 patients from 1965 to 1987. J Pediatr Surg 23(8): 744-748.

2. Herrera P, Caldarone C, Forte V, Campisi P, Holtby H, et al. (2007) The current state of congenital tracheal stenosis. Pediatr Surg Int 23(11):1033-1044.

3. Hoffer M, Tom L, Wetmore R (1994) Congenital tracheal stenosis. The otolaryngologist's perspective. Arch Otolaryngol Head Neck Surg 120(4): 449-53.

4. Kussman BD, Geva T, McGowan FX (2004) Cardiovascular causes of airway compression. Paediatr Anaesth 14(1): 60-74.

5. Wijeweera 0, Ng SB (A2011) Retrospective review of tracheoplasty for congenital tracheal stenosis. Singapore Med J 52(10): 726-29.

6. Chao YC, Peng CC, Lee KS, Lin SM, Chen MR (2016) The association of congenital tracheobronchial stenosis and cardiovascular anomalies. Int J Pediatr Otorhinolaryngol 83: 1-6.

7. Antón Pacheco JL, Cano I, Comas J, Galletti L, Polo L, et al. (2006) Management of congenital tracheal stenosis in infancy. Eur J Cardiothorac Surg 29(6): 991-996.

8. Tsang V, Murday A, Gillbe C (1989) Slide tracheoplasty for congenital funnel-shaped tracheal stenosis. Ann Thorac Surg 48(5): 632-635.

9. Yang JH, Jun TG, Sung K, Choi JH, Lee YT, et al. (2007) Repair of longsegment congenital tracheal stenosis. J Korean Med Sci 22(3): 491-496.

10. Macchiarini P, Dulmet E, de Montpreville V, Mazmanian GM, Chapelier A, et al. (1997) Tracheal growth after slide tracheoplasty. J Thorac Cardiovasc Surg 113(3): 558-566.

11. Wang S, Zhang H, Zhu L, Zhen J, Liu J, et al. (2016) Surgical management of congenital tracheal stenosis associated with tracheal bronchus and congenital heart disease. Eur J Cardiothorac Surg 49(4):1201-1206.

12. Elliott M, Roebuck D, Noctor C, McLaren C, Hartley B, et al. (2003) The management of congenital tracheal stenosis. Int J Pediatr Otorhinolaryngol 67 Suppl 1: S183-S192.

13. Pullens B, Hoeve LJ, Timmerman MK, van der Schroeff MP, Joosten KF (2014) Characteristics and surgical outcome of 98 infants and children surgically treated for a laryngotracheal stenosis after endotracheal intubation: excellent outcome for higher grades of stenosis after SSLTR. Int J Pediatr Otorhinolaryngol Sep 78(9):1444-1448.

14. Sandu K, Monnier P (2007) Congenital tracheal anomalies. Otolaryngol Clin North Am 40(1): 193-217. 
CC (i) Commons Attribution 4.0 License BY

DOI: 10.19080/GJO.2018.15.555922
Your next submission with Juniper Publishers will reach you the below assets

- Quality Editorial service

- Swift Peer Review

- Reprints availability

- E-prints Service

- Manuscript Podcast for convenient understanding

- Global attainment for your research

- Manuscript accessibility in different formats

( Pdf, E-pub, Full Text, Audio)

- Unceasing customer service

Track the below URL for one-step submission https://juniperpublishers.com/online-submission.php 